\title{
Classroom training strategies to strengthen the hotbed of research in architecture
}

\author{
Rolando-Arturo Cubillos-González \\ e-mail:racubillos@ucatolica.edu.co \\ Architecture program / Design Faculty / Universidad Católica de Colombia
}

\begin{abstract}
The Architecture program at the Catholic University of Colombia needs to strengthen the research processes within its classrooms and consequently, it is important to make a direct link with the hotbeds of research. In this context, it is worth asking what the best classroom training strategy to link and strengthen the architectural hotbed of research would be. The objective of this article is to explain said strategy. The results of this exercise were: first, the identification and formulation of a research training strategy applied to the eighth, ninth and tenth semesters of the Architecture programme. This applied exercise changed the didactic means of teaching research competencies to the students in order to better organise their innovative ideas through systematised processes. This enabled the development of collaborative work experience oriented towards scientific research within the classroom, in a very short time.
\end{abstract}

Keywords: Hotbed of Research, Research skills, Training Strategies, Computer Application.

\section{Introduction}

The Architecture program at the Catholic University of Colombia needs to strengthen research processes within its classrooms. To do this, it was proposed that the leaders of the Hotbeds of Research should formulate classroom training strategies, aimed at developing research skills among students of the program. Therefore, in response to this need, in the seedbed Computer Applications in Architecture (CAA) the investigative abilities a student requires to develop their training process were identified, so that they can analyse the characteristics of the impacts of climate change on the urban habitat, proposing solutions for mitigation and adaptation.

The CAA hotbed of Research was oriented towards two fundamental study problems. The first being climate change and the second habitability. Sustainable technologies, sustainable environments and technological environments were defined as the three areas of study. The intersection of these three areas are the three following lines of research (Figure 1):

- The first is the relationship between sustainable and environmental technologies, resulting in modelling processes. In this line the following question is asked: What I am going to do? This is answered through sustainable design.

- The second is the relationship between sustainable technologies and technological environments, resulting in the use of simulation processes. In this line the following question arises: How am I going to do it? This is solved through sustainable management.

- Third, the relationship between the sustainable environment and technological environments results in experimentation. In this line, the question is proposed: When and under what conditions am I going to do it? This is met through technological development.

For these reasons, the study was of an experimental and exploratory nature. It focused on the development of four techniques: reverse engineering, quality matrix QDF, Business Model Canvas (Osterwalder, 2011; Clark, 2012) and business plan tools from Information and Communication Technologies (ICT). For this study, the open WikiHouse (Parvin, 2013) was selected as an object of study, as it is an innovative development product. 
With this system the study sought to develop three types of innovation: incremental, fundamental or radical. Therefore, the design of the proposed methodology focused on the development of investigative skills needed to train students in the area of integrated design (Trebilcock, 2009).

To achieve this, some of the investigatory abilities proposed by the Catholic University of Colombia (2007) were used:

- First, personal skills focused on adapting to change.

- Second, intellectual skills focused on decision making and problem solving.

- Third, interpersonal skills that were based on teamwork and leadership.

- Fourth, organizational skills based on information management and resource management.

- Fifth, technological skills concentrated on identifying innovation processes.

- Finally, labour skills were based on the design of processes and products.

One might ask what would be the best strategy to develop research training in the classroom. The aim of this article is to explain said strategy, which was developed in the field of the research hotbed "Computer Applications in Architecture" (CAA). The results of this exercise were: first, the identification and formulation of a research training strategy applied to the classroom.

Second, the development of research skills in students of semesters eight, nine and ten of the Architecture program. Finally, the methodology developed, the partial results of the implementation of the training strategy, and the discussion and conclusions of this study will now be presented.

\section{$\mathrm{CAA}^{*}=$ Computer Applications in Architecture}

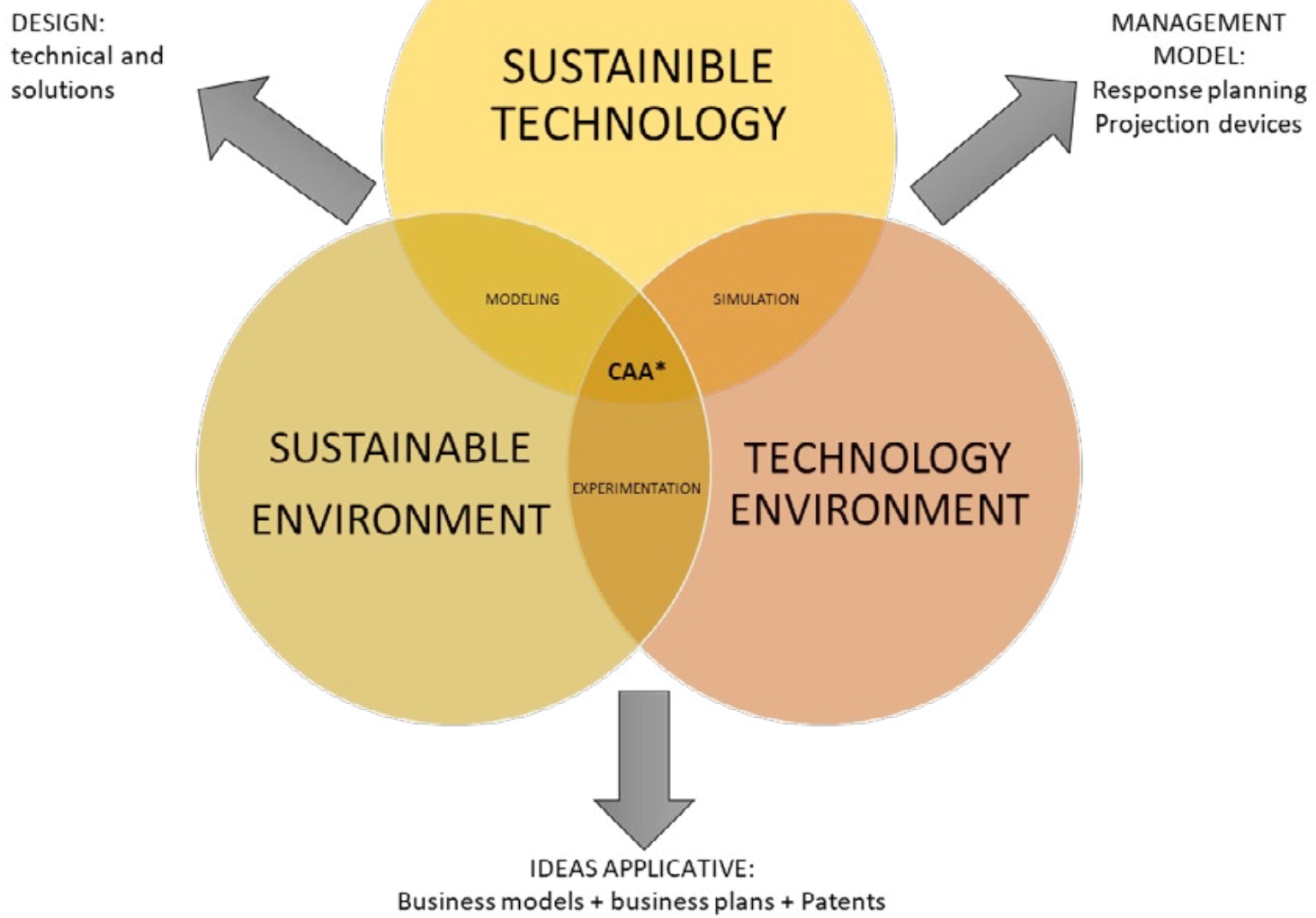

Fig. 1. Computer Applications in Architecture hotbed of Research framework. Prepared by the author. 


\section{Methodology}

The process of training in investigative skills is composed of four stages (Figure 2):

- Reverse engineering: is a process of analysis that seeks the cutting of a product, to produce a process of technological innovation from existing elements. To achieve this it uses computer systems and technological tools (Cubillos-Gonzalez, 2011).

- Matrix product planning QFD (Quality Function Deployment): is a concurrent engineering (CE) technique and consists of a planning process for new products driven by customer needs to be carried out by the CE team (Beard, 2001; Riba, 2010; 2006).

- Model Canvas: is a method that builds a language to describe and easily manage a business model in order to develop new strategic alternatives (Osterwalder et al, 2011, 18).

- Proposal for entrepreneurship using IT tools: is the management of a business model through the implementation of computing platforms that enable the processing of information in real time (Tooze et al, 2014).

\section{METHODOLOGY FOR THE DEVELOPMENT PROCESS OF SOFTWARE APPLICATIONS AIMED AT TECHNOLOGICAL INNOVATION}

Research+Develop (R+D) + Innovation Method:

Reverse engineering

- Technological analysis

- Techonlogical path

- Technological monitoring

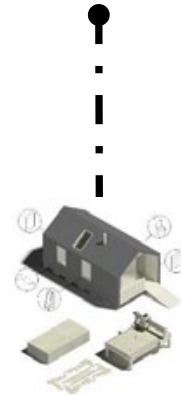

WiKiHouse

BUSINESS MODEL

Method:

Canvas

- Business idea

- Business plan
Analysis

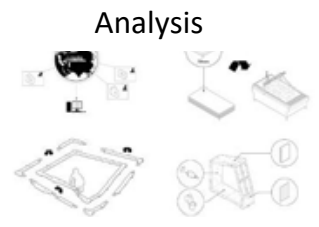

SOURCE: www.wikihouse.CC (2015)
ORGANIZATIONAL STRUCTURE

Method:

Concurrent engineering

- Types of work group.

- Colaborative work strategies.

- Production and product quality strategies.
PROPOSALS USING IT TOOLS.

Method:

Enterprise proposals

-Spin-Off

-Patents and registrations.

Fig. 2. Study Methodology. Prepared by the author.

To develop the exercise, it was applied in four courses of the architecture program, one during the day and another in the evening (From figure 3 to figure 6), for two elective semesters (one year). The exercise was applied in the elective Information and Communication Technologies. Each course consisted of 20 students and four groups of five students were formed per course. The procedure that was followed was composed of five steps organized below:

- Technological analysis: it is intended that students identify the various innovation possibilities that can be made from the study of an existing object through reverse engineering.

- The establishment of teams: consisted of selecting the type of collaborative team that will develop the process of technological innovation (Cubillos-Gonzalez, 2012; Nieto, 2010). Whether this be functional, matrix or self-contained.

- Production techniques and product quality: the organization, production and quality management from the study of the QFD matrix were analysed. 
- Business model and business plan: once the innovation process was developed, the business model was designed, thus enabling the transfer of technology to the market.

- Spin-off: to propose a technological development project derived from scientific research process in order to optimally place the innovation product in the market.
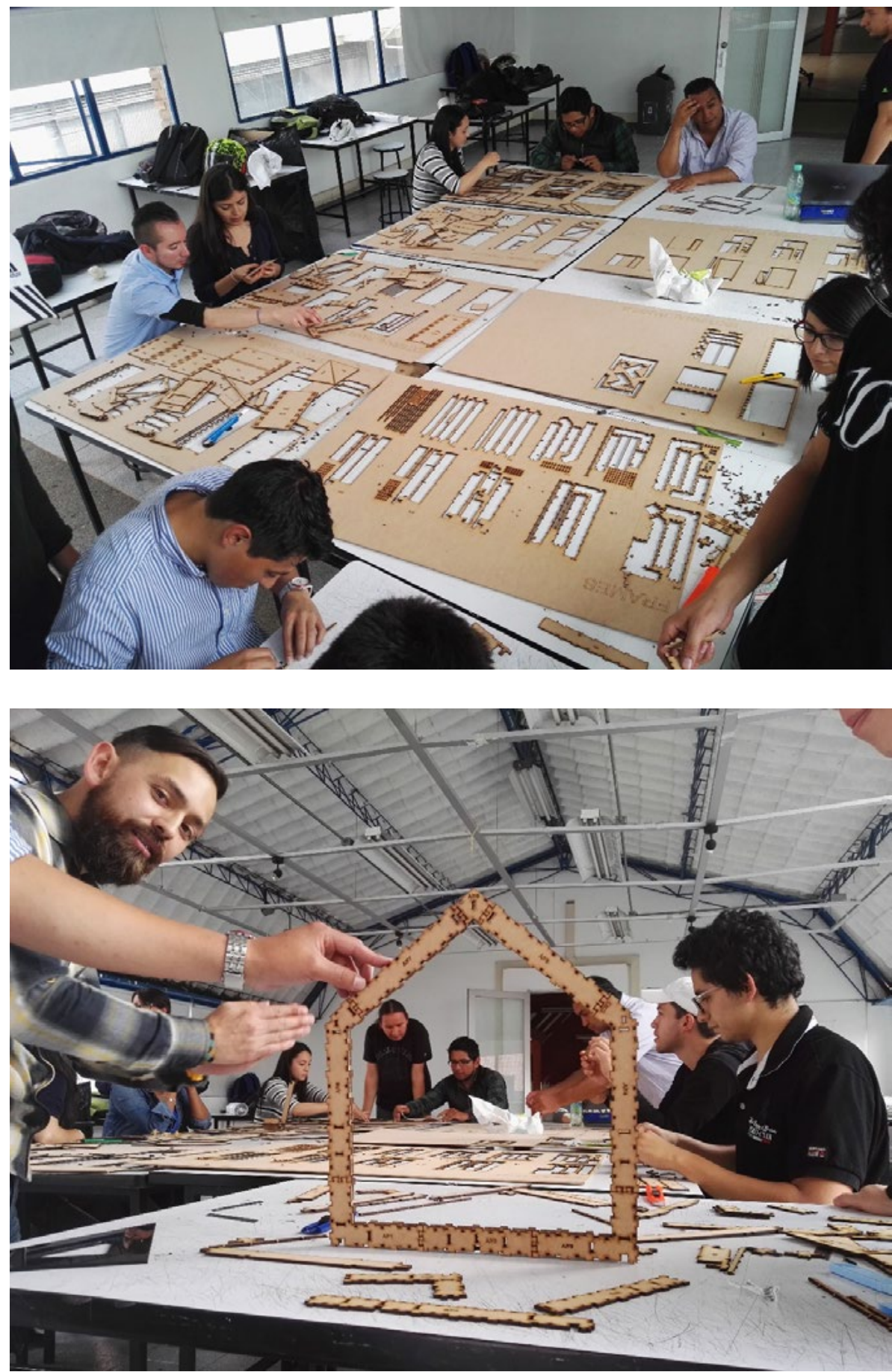

Fig. 3. Day course student work. Prepared by the author.
Fig. 4. Day course student work. Prepared by the author. 

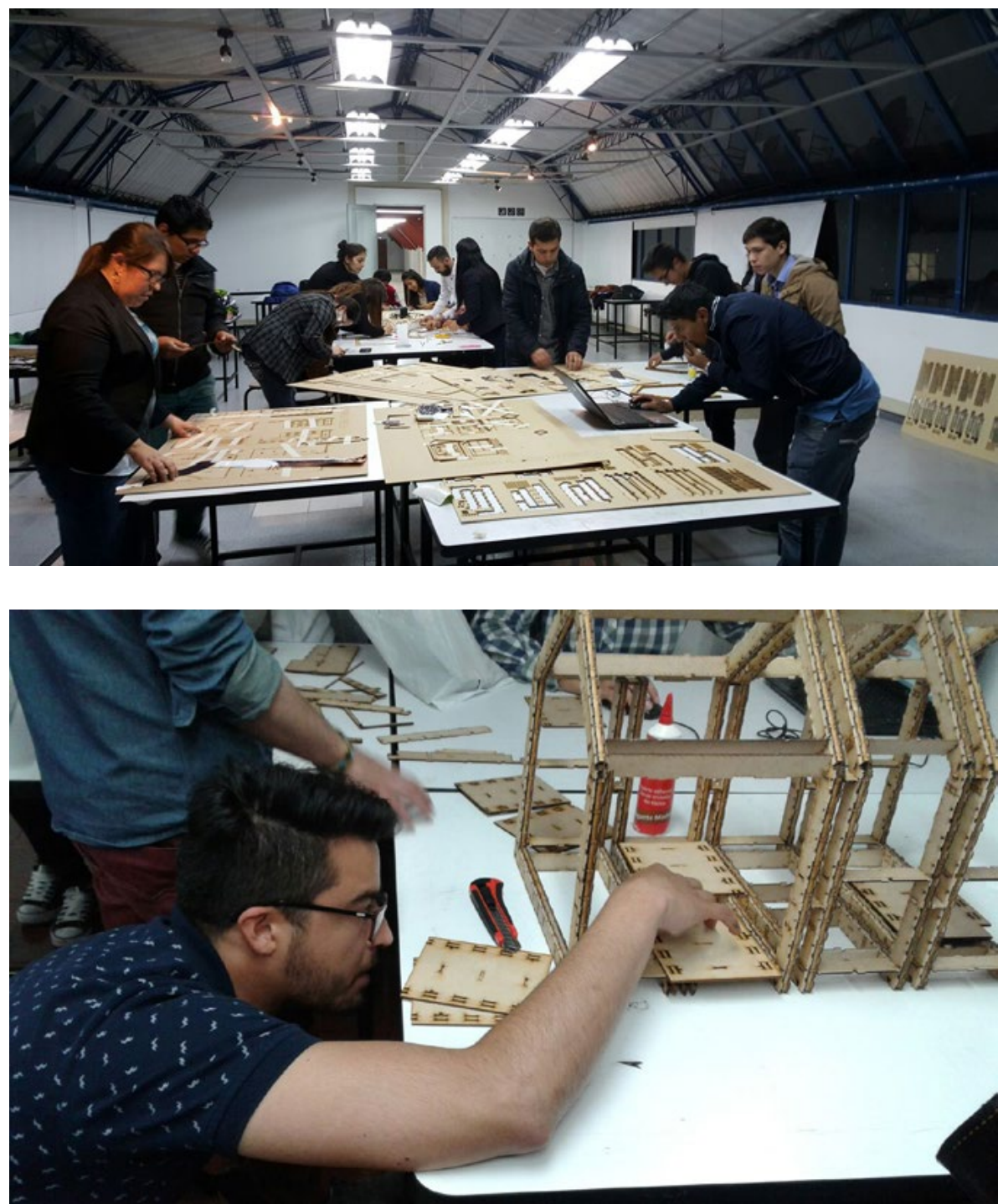

\section{Methodology evaluation training in classroom}

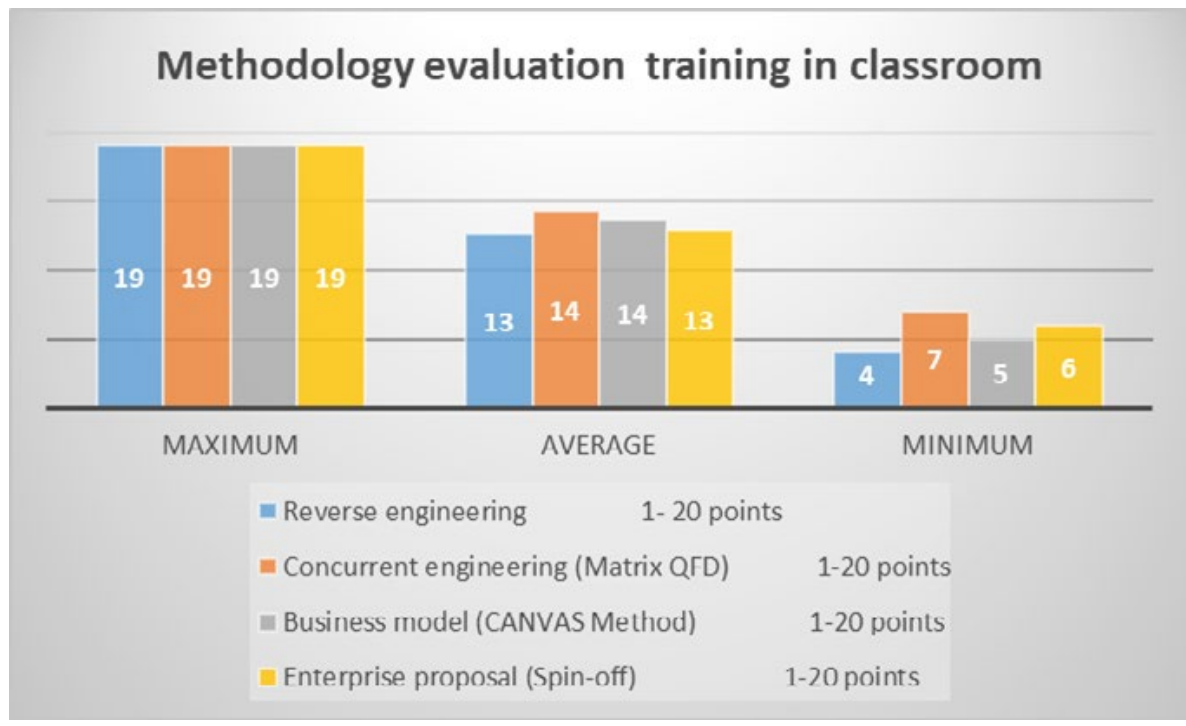

Fig. 5. Evening course student work. Prepared by the author.
Fig. 6. Evening course student work. Prepared by the author.

Chart 1. Student work results first semester. Prepared by the author. 


\section{Student work results}

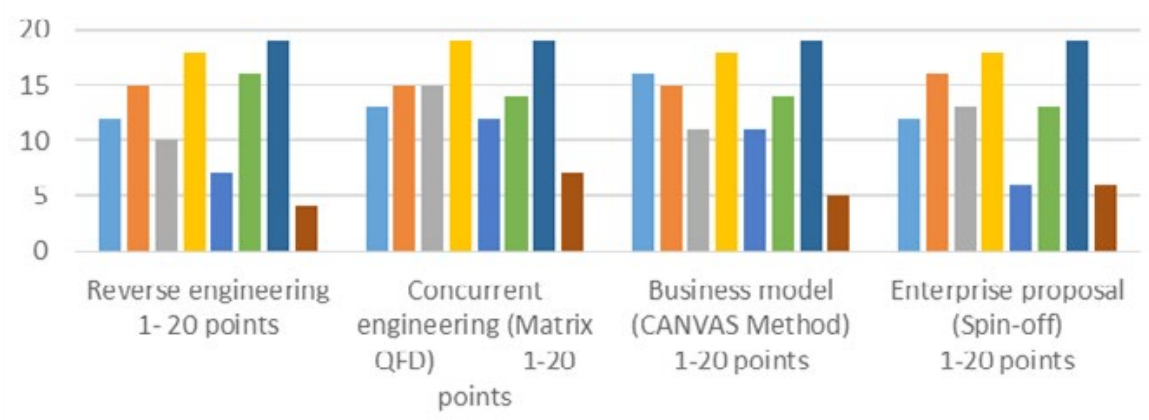

- Course 01 / Daytime G-1 a Course 01 / Daytime G-2 = Course 01/ Daytime G-3

a Course 01 / Daytime G-4 a Course 02 / Evening G-5 a Course 02 / Evening G-6

- Course 02 / Evening G-7 course 02 / Evening G-8

Chart 2. Student work results first semester. Prepared by the author.

\section{Methodology evaluation training in classroom}

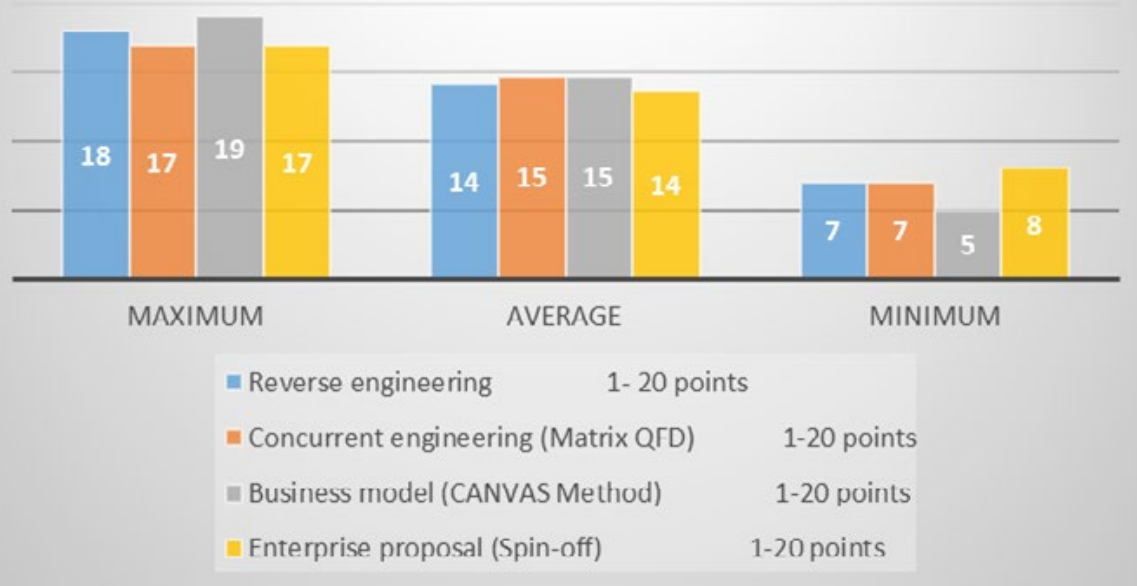

\section{Student work results}

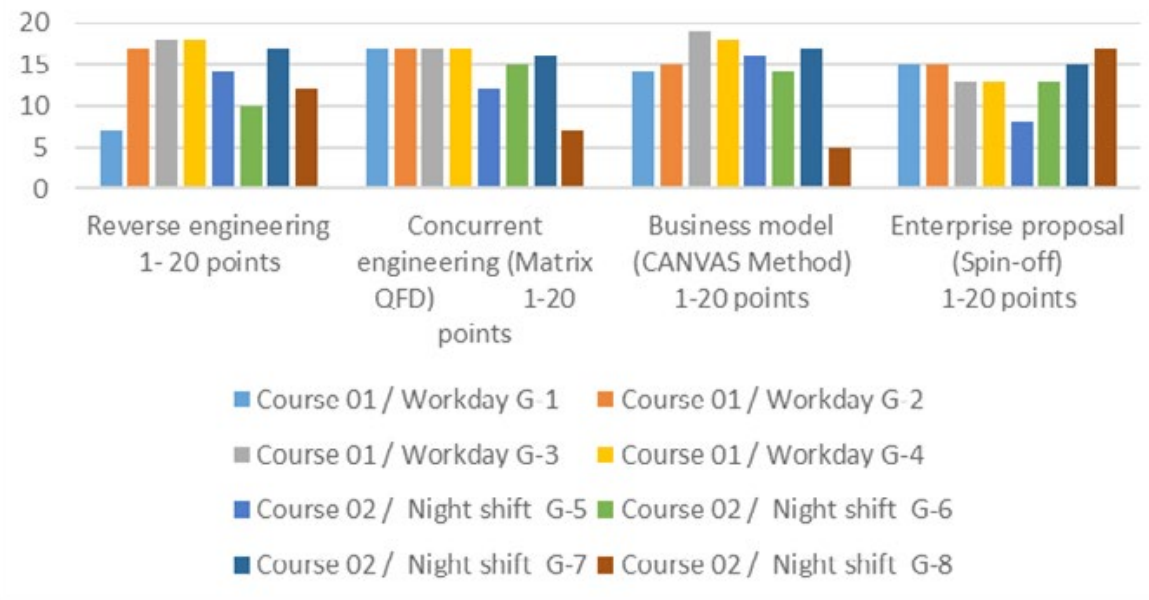

Chart 3. Student work results second semester. Prepared by the author.

Chart 4. Student work results second semester. Prepared by the author 
Table 1. Datasheet fieldwork results. Prepared by the author.

\begin{tabular}{|ccccccc|}
\hline Item & \multicolumn{2}{c}{ First semester } & \multicolumn{2}{c|}{ Second semester } & \multicolumn{2}{c|}{ Partial results } \\
\hline $\mathbf{8}$ groups & No & $\%$ & No & $\%$ & $\begin{array}{c}\text { Total groups } \\
\text { (No) }\end{array}$ & $\begin{array}{c}\text { Total } \\
\text { average (\%) }\end{array}$ \\
\hline Optimal results & 1 & 12.50 & 0 & 0.00 & 1.00 & 6.25 \\
\hline Good results & 4 & 50.00 & 0 & 0.00 & 4.00 & 25.00 \\
\hline Regular results & 2 & 25.00 & 4 & 50.00 & 6.00 & 37.50 \\
\hline Poor results & 1 & 12.50 & 4 & 50.00 & 5.00 & 31.25 \\
\hline Total & $\mathbf{8}$ & $\mathbf{1 0 0 . 0 0}$ & $\mathbf{8}$ & $\mathbf{1 0 0 . 0 0}$ & $\mathbf{1 6 . 0 0}$ & $\mathbf{1 0 0 . 0 0}$ \\
\hline
\end{tabular}

Table 2. Datasheet fieldwork results. Prepared by the author.

\begin{tabular}{|c|cccc|}
\hline Item & $\begin{array}{c}\text { Reverse } \\
\text { engineering }\end{array}$ & $\begin{array}{c}\text { Concurrent } \\
\text { engineering } \\
\text { (Matrix QFD) }\end{array}$ & $\begin{array}{c}\text { Business model } \\
\text { (CANVAS Method) }\end{array}$ & $\begin{array}{c}\text { Enterprise } \\
\text { proposal (Spin-Off) }\end{array}$ \\
\hline First semester & $24 \%$ & $27 \%$ & $26 \%$ & $24 \%$ \\
\hline Second semester & $25 \%$ & $26 \%$ & $26 \%$ & $24 \%$ \\
\hline Average & $\mathbf{2 4 \%}$ & $\mathbf{2 6 \%}$ & $\mathbf{2 6 \%}$ & $\mathbf{2 4 \%}$ \\
\hline
\end{tabular}

\section{Results}

The results of the application of the exercise in first semester classes were as follows:

Of the eight working groups, one evening group achieved optimal results representing $12.5 \%$ additionally, a different evening group performed poorly, and representing $12.5 \%$ of the total sample. Furthermore, four groups achieved satisfactory results representing 50\%. Two of these were daytime groups and two were evening groups. Finally, two groups achieved consistent results, representing $25 \%$.

It is noted that in the 4 daytime groups the results are even; $75 \%$ of them are in a range of good results, while only $25 \%$ yielded regular results. Also for the evening groups the results are different, dividing evenly between bad, regular, good and excellent with $25 \%$ representation for each endpoint.

It is noted that the learning stages for the eight groups are similar, where $24 \%$ of the groups assimilated the stage of reverse engineering, while $27 \%$ of the groups assimilated the stage of Concurrent Engineering (Matrix QFD). 26\% of the groups assimilated the application of the model Canvas.

Finally, $24 \%$ of the groups assimilated the Spin-Off stage. Two graphs that show the maximum, average and minimum achieved by the working groups are presented below. The scores obtained by groups at each stage of the proposed methodology (Chart 1 and 2) are also shown.

On the other hand, the results of the application of the exercise in the second semester classes were: Of the eight working groups, four groups achieved consistent results representing $50 \%$, of these only one group was during the evening. Finally, four groups achieved poor results with a representation of $50 \%$ of the total sample. It is noted that in the daytime classes the results of the four groups are uniform, with $75 \%$ of them in a range of regular results, while only $25 \%$ yield poor results. For evening classes the results are poor with $75 \%$ representation for each endpoint and only $25 \%$ yielding good results.

It is noted that the learning stages for the eight groups are homogeneous, where $25 \%$ of the groups assimilated the stage of reverse engineering, while $26 \%$ of the groups assimilated the stage of Concurrent Engineering (Matrix QFD). 26\% of the groups assimilated the application of the model Canvas. Finally, $24 \%$ of the groups assimilated the Spin-Off stage.

Below are two graphs that show the maximum, average and minimum achieved by the working groups in the second half. Additionally, in these graphs the scores obtained by groups at each stage of the proposed methodology are shown (Chart 3 and 4). 
Finally, when comparing the two exercises applied to each semester, it is clear that the first half achieves better and more diverse results, compared with the second half which obtained between regular and poor results that are balanced.

With regards to the development of the process, a considerable difference in learning occurs in the first two stages, ranging from $24 \%$ to $27 \%$. As for the last two stages, homogeneity is presented with a learning percentage of $26 \%$ in the penultimate stage and $24 \%$ in the last stage. This indicates that in the first stages students find it more difficult to analyse work references, but once they have overcome these stages an improved development of the exercise is noted (Table 1 and 2).

\section{Discussion}

As mentioned earlier in this article, the aim of this paper was to explain the implementation of a strategy to link classroom training and strengthen seed research within the Architecture program at the Catholic University of Colombia. As a result of this it was possible to identify how to apply the six investigative abilities a student needs in order to develop his training process within the context of analyzing the impact produced by climate change in the urban habitat.

The use of innovation and research processes made it possible to equate difficulties in order to build sustainable technologies and environments in the early stages of the process. It should be noted that in these stages skills such as adaptation to change, problem solving and teamwork are essential. As established in the results, this learning process is not homogeneous in the last three semesters.

For this reason it is necessary to emphasize the teaching proposal to fill conceptual gaps that students may have acquired during their training process. It is therefore necessary to identify future relations between different subjects in the first semester of the program, so that students can appropriately develop the investigative process in their last semesters.

On the other hand, it is clear that by overcoming the early stages of the process it is much easier for students to propose sustainable technologies and rapidly create technological environments. At this point, the use of techniques such as reverse engineering and concurrent engineering are essential.

They reinforce skills such as information and resource management with which students are appropriately oriented towards identifying innovation processes in order to do this, the resource business model from the Canvas technique allows them to systematize processes and connect research results with business plans.

Here it is important to note that the term business model refers to a broader concept than just a financial model. Finally the last stages of the strategy allow for the effective linking of the sustainable environment and technological environments. According to the results discussed above (Figures 1 and 3), these two stages allow one to perceive that students can develop processes of innovation and entrepreneurship once they have assimilated the skills of the early stages.

However, the results have found that in the evening classes it is much harder to develop the research training strategy. One reason is that students of the evening classes do not have sufficient time and they also form part of the labour force, which does not allow them to devote enough time to the research process. It is recommended that the training processes of the evening classes are evaluated, in order to propose a teaching method that suits the time schedules of these students.

\section{Conclusions}

As a summary, it is noted that it is necessary to introduce research training processes in the courses of the Architecture program in the School of Design. This involves giving a systemized vision of the process of sustainable design, which today is more oriented to innovation and industrialization with the aim of reducing environmental impact.

However, these processes require that the investigative training process is more applications, so that students can understand and incorporate these concepts into their daily work. Innovation processes are rigorous 
and are closely linked to research processes. That is why the incorporation of research training methodologies from the hotbeds of research can be a contribution to the architecture program and its different electives.

In conclusion, this first applicative exercise changed the didactic teaching method of investigative abilities in students of eighth, ninth and tenth semesters of the Architecture program. Students learned to organize their ideas through systematic innovation processes that allowed them to develop IT tools that can then be transferred to the productive sector through business ideas that are oriented to respond to climate change.

To do this, the proposed methodology was applied in the classroom, enabling the simulation of an appropriate environment for research and innovation. It allowed the development of collaborative research orientated work in a short period of time. In the future it is hoped that this strategy will be strengthened and incorporated into the formative processes of the Architecture program at the Catholic University of Colombia.

\section{Acknowledgemen}

Special Thanks to Vicky Cox who's made the editing style of this article.

\section{References}

[1] Barba, E. (2001). Concurrent Engineering: A Guide for implementation in the company, diagnosis and evaluation [Ingeniería concurrente: guía para su implantación en la empresa, diagnóstico y evaluación]. Gestión 2000.

[2] Clark, T., Osterwalder, A., \& Pigneur, Y. (2012). Business model you: a one-page method for reinventing your career. John Wiley \& Sons.

[3] Cubillos-González, R. (2011). Technological development impact in the architecture field. [El impacto del desarrollo tecnológico en arquitectura]. ARKA Revista de Arquitectura, 3, 54-61.

[4] Cubillos-González, R. (2012). Collaborative environments design through IT tools. [Diseño de Entornos Colaborativos a Través de Herramientas TIC]. ARKA Revista de Arquitectura, 2, 78-91.

[5] Nieto, J. (2010). And you...innovate or abdicate? [Y tú... ¿Innovas o abdicas?]. Valencia. Editorial Universitat Politécnica de València.

[6] Osterwalder, A., \& Pigneur, Y. (2010). Business model generation: a handbook for visionaries, game changers, and challengers. John Wiley \& Sons.

[7] Parvin, A. 2013. Architecture (and the other 99\%): Open-Source Architecture and Design Commons. Architectural Design, 83(6), 90-95.

[8] Riba, C. (2010). Concurrent design [Diseño concurrente]. Universidad Politèc. de Catalunya. Ediciones UPC.

[9] Riba, C., \& Molina, A. (2006). Concurrent design: an integrated methodology [Ingeniería concurrente - una metodología integradora]. Universidad Politèc. de Catalunya. Ediciones UPC, 314.

[10] Trebilcock, M. (2009). Integrated Design Process: New paradigms in sustainable architecture [Proceso de Diseño Integrado: nuevos paradigmas en arquitectura sustentable]. Arquitetura Revista, 5(2), 65-75.

[11] Tooze, J., Baurley, S., Phillips, R., Smith, P., Foote, E., \& Silve, S. (2014). Open Design: Contributions, Solutions, Processes and Projects. The Design Journal, 17(4), 538-559.

[12] Universidad Católica de Colombia (2007). Investigative skills to research training [Competencias investigativas para la formación en investigación]. Editorial Universidad Católica de Colombia. 